\title{
Nutritional benefits of flavocoxid in patients with osteoarthritis: efficacy and safety
}

\author{
This article was published in the following Dove Press journal: \\ Nutrition and Dietary Supplements \\ 13 May 2010 \\ Number of times this article has been viewed
}

\author{
Robert M Levy' \\ Lakshmi Pillai \\ Bruce P Burnett ${ }^{2}$ \\ 'Department of Clinical Development, \\ ${ }^{2}$ Department of Medical Education \\ and Scientific Affairs, Primus \\ Pharmaceuticals, Inc., Scottsdale, \\ AZ, USA
}

\begin{abstract}
Osteoarthritis (OA) is a major age-related, chronic disease in the United States that results in significant morbidity and functional loss as well as substantial financial outlay. Dietary habits have been shown to influence the metabolic and inflammatory processes involved in OA. For example, a lower intake of antioxidants is associated with increased incidence of OA while an increased intake of flavonoids and omega-3 polyunsaturated acids decreases production of inflammatory mediators and the incidence of OA. These observations argue that dietary habits contribute to the metabolic and inflammatory etiology of chronic diseases such as OA. Flavocoxid is a botanically-based formula composed of concentrated and standardized flavonoids from the botanicals Scutellaria baicalensis and Acacia catechu. Flavonoids constitute a large class of compounds known as polyphenols, ubiquitous in plants and consumed regularly in the human diet. Flavocoxid was developed by extensive high throughput screening and enzymatic testing and two specific flavonoids, catechin and baicalin, were identified that possess potent anti-inflammatory properties. Flavocoxid acts by managing both the cyclooxygenase and 5-lipoxygenase pathways of arachidonic acid metabolism thought to underlie the pathological processes of OA. Preclinical and clinical evidence suggests that flavocoxid provides effective and safe dietary management of the underlying metabolic processes of OA.
\end{abstract}

Keywords: cyclooxygenase, 5-lipoxygenase, inflammation, flavonoids

\section{Introduction}

Humans have sought and used botanical products for medicinal purposes for thousands of years. Many of the pharmaceuticals in use today are purified extracts or derivatives of substances of botanical origin. ${ }^{1}$ Ethnopharmacology has become a major scientific specialty both academically and commercially with a number of pharmaceutical companies devoting a portion of their research and development budgets to exploration in areas such as the Amazon basin, Africa, the South Pacific, and East and Southeast Asia, generally with teams of ethnobotanists, biochemists, pharmacologists, and anthropologists. Many compounds have been "discovered" that have biologic activity on almost all physiologic systems and processes from cancer to ulcers, headaches to arthritis, goiters to heart function. ${ }^{2,3}$ Among these, flavonoids, with more than 9,000 molecular species described, have been found to have activity in many physiological systems. With the rapid extinction or absorption of indigenous peoples, it is feared that much traditional, orally transmitted, therapeutic knowledge will be lost thereby making the discovery of botanically-based therapeutic molecules more difficult by requiring more "random" sampling of botanical sources.
Correspondence: Robert M Levy

Primus Pharmaceuticals, Inc.,

4725 N Scottsdale Rd, Suite 200,

Scottsdale, AZ 8525I, USA

Tel $+\mid 480583$ |4 I0

Fax +I 4804832604

Email rlevy@primusrx.com 
Though flavonoid molecules have been known for decades to possess anti-inflammatory activity, only recently have any of these molecules entered OA clinical trials and found their way to market. This report will focus on the detailed preclinical and clinical investigation of flavocoxid, an anti-inflammatory medical food composition marketed for the metabolic management of OA under the brand name Limbrel $^{\circledR}$. Other flavonoid-based formulations have been tested in small, pilot clinical studies. For example, flavonoid extracts from Garcinia kola were equivalent to naproxen and celecoxib and better than placebo in addressing the pain, stiffness, and mobility of OA patients $(\mathrm{n}=21)^{4}$ and, in pilot, randomized double-blind studies, pine bark extracts $\left(\right.$ Pycnogenol $^{\circledR}$ ) improved Western Ontario and McMaster University Osteoarthritis Index (WOMAC) composite scores for pain, stiffness, and mobility compared to the placebo control groups..$^{5-7}$ Limbrel, however, is the only flavonoid, anti-inflammatory therapeutic currently marketed in the United States as a prescription therapeutic for OA.

\section{OA: prevalence and costs}

$\mathrm{OA}$ is the leading cause of musculoskeletal morbidity and functional loss in humans, its effects increasing with advancing age..$^{8-10}$ In the US, it is estimated that $25 \%$ of people age 55 and over or as many as 40 million people have knee pain, and at least half of this population has had a radiographic diagnosis of OA..$^{11,12}$ The prevalence of $\mathrm{OA}$ is expected to increase to 60 million by the year 2020 as the population ages. ${ }^{13} \mathrm{In}$ 2001, the estimated prevalence of self-reported chronic joint pain was $33 \%$ of adults 18 and older, of which $10 \%$ carried a medical diagnosis of arthritis. Although the type of joint disease was not specified in this survey, OA was certainly the major component. ${ }^{13}$ Data from the National Center for Health Statistics 2006 Health Interview Survey reveals that $25 \%$ of adults aged over 18 years had chronic joint symptoms and $21 \%$ of adults were told by a health professional that they had arthritis. These statistics are almost identical to British data reported by Peat et al. ${ }^{11}$ Not surprisingly, while only $6.9 \%$ of people aged 18-44 years carried a diagnosis of arthritis, the incidence increased to $28.7 \%$ between the ages of $45-64$ years, $48 \%$ between $65-74$ years, and remained relatively constant at $51.3 \%$ above 75 years. ${ }^{14} \mathrm{OA}$ is a major cause of impaired mobility and expected to be the fourth leading cause of disability in the US and Western Europe by the year 2020. ${ }^{8,15,16}$ This has significant societal and financial implications. By one recent estimate, the average annual costs per person in an insured population of OA patients was $\$ 8,601$ for direct medical costs including treatment of drug induced side effects, $\$ 2,941$ for drugs, and $\$ 4,603$ for indirect costs such as time lost from work. ${ }^{17}$ These data are remarkably consistent across time and populations. ${ }^{9,18-21}$ Reginster $^{22}$ estimated the cost of all forms of arthritis at between 1\%-2.5\% of GNP for all Western nations and noted that poor quality of life issues related to arthritis exceeded those for gastrointestinal, respiratory, and cardiovascular diseases. ${ }^{22}$

When evaluating the results of clinical, epidemiological, or socio-economic studies, it is important to understand the population under consideration, since approximately $50 \%$ of adults aged over 55 years with knee pain do not have radiographic evidence of OA and an equal percentage with radiographic OA do not have pain. ${ }^{11,23}$ Furthermore, when considering symptomatic, structural, or functional significance of disease or therapeutic intervention, the pattern of joint involvement must be defined. For example, aside from the concept of pain, impairment of mobility from OA of the hip or knee raises entirely different quality of life (QOL) and activities of daily living (ADL) issues than those arising from the impairment of fine motor function that accompanies moderate-severe hand OA.

\section{Metabolic considerations in OA}

The etiology of OA is multifactorial including things such as trauma, inflammation, obesity, and genetic predisposition. It is only relatively recently that, with a substantial increase in our understanding of the biochemical processes involved in the degradation and repair of articular cartilage and subchondral bone, the etiologic roles of nutritional factors and lifestyle have become more appreciated.

Much of the tissue injury and symptoms of pain and stiffness has been demonstrated to be related to products generated by metabolism of arachidonic acid (AA) derived from dietary intake and of cell membrane phospholipids by the action of phospholipase-A2. Conversion of AA to pro-inflammatory mediators proceeds by parallel enzymatic and oxidative pathways (Figure 1).24,25

Production of prostaglandins $\left(\mathrm{PGI}_{2}, \mathrm{PGE}_{2}, \mathrm{PGF}_{2}\right)$ and leukotrienes, particularly $\mathrm{LTB}_{4}, \mathrm{LTC}_{4}$, and $\mathrm{LTD}_{4}$, the end products of the cyclooxengenase (COX-1, COX-2) and 5-lipoxengenase (5-LOX) systems, respectively, results in recruitment of inflammatory cells and fluid as well as induction of cytokines, metalloproteinases, and other agents that contribute to cartilage breakdown and impairment of normal reparative processes. ${ }^{25}$ An imbalance of thromboxanes and prostacyclins (from relatively excessive COX-1 or COX 2 inhibition, respectively) may account for some or most of the antiplatelet and cardiovascular toxicity seen with these agents, primarily caused by vasoconstriction of arteries, ultimately leading 


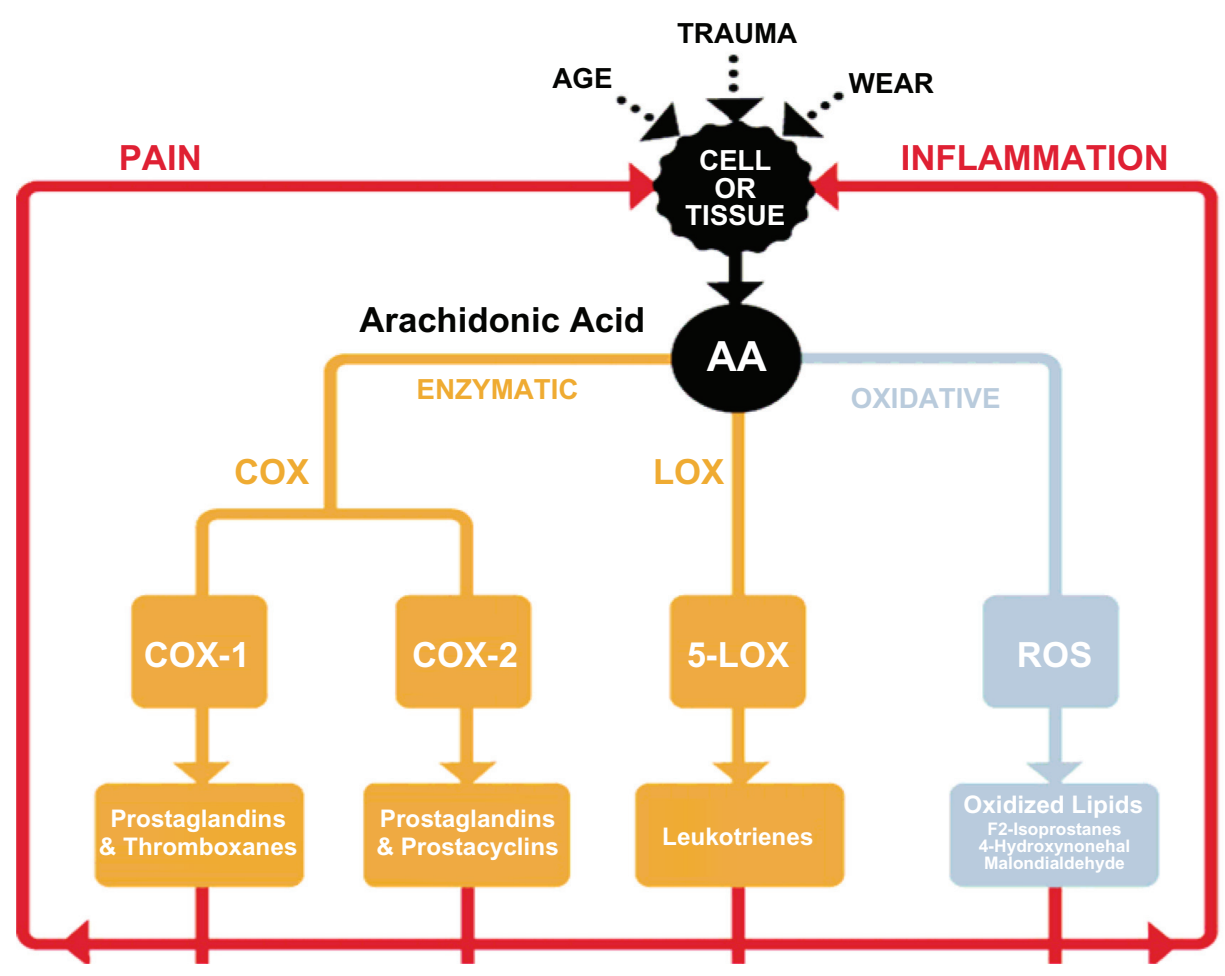

Figure I Metabolic pathways of arachidonic acid metabolism. AA is enzymatically metabolized to various prostaglandins, thromboxanes, prostacyclins, and leukotrienes through the COX-I, COX-2, and 5-LOX pathways. AA can also be oxidatively metabolized though the action of ROS to form inflammatory lipids such as isoprostanes, which are known to be elevated in the joints of OA patients

Abbreviations: AA, arachidonic acid; COX, cyclooxygenase; 5-LOX, 5-lipoxygenase; ROS, reactive oxygen species.

to edema, stroke, and myocardial infarction. ${ }^{26}$ Different nonsteroidal anti-inflammatory drugs (NSAIDs) are either more COX-1 or COX-2 selective or relatively balanced on these two pathways. ${ }^{27}$ For example, rofecoxib and valdecoxib are highly inhibitory for the cyclooxygenase activity of COX-2, while indomethacin, flurbiprofen, and ketorolac are highly inhibitory for the cyclooxygenase activity of COX-1. Sodium salicylate, due to its inherent mechanism of action, is a relatively balanced inhibitor of cyclooxygenase activity for COX-1 and COX-2.27

In the VIGOR trial, rofecoxib showed a four fold increase in cardiovascular events (heart attack, stroke, and blood pressure changes) compared with naproxen. ${ }^{28} \mathrm{~A}$ retrospective study of over 54,000 patients in two different health plan analyses demonstrated a three fold increase in heart attack over placebo among elderly adults in the first 90 days when taking $>25 \mathrm{mg}$ per day of rofecoxib. ${ }^{29}$ Similarly, valdecoxib showed cardiovascular complications after cardiac surgery and in retrospective analysis of several clinical trials. ${ }^{30}$ Finally, celecoxib has been shown to increase heart attacks, stroke, and other cardiovascular complications in a dose dependent manner $(2.3 \%$ at $200 \mathrm{mg}$ per day, $3.4 \%$ at $400 \mathrm{mg}$ per day). ${ }^{31}$ Rofecoxib was voluntarily withdrawn from the market in late 2004 and valdecoxib was withdrawn in early 2005. In February 2005, a Food and Drug
Administration (FDA) advisory committee did not recommend that celecoxib be removed from the market, but recommended new "black box" warnings for all NSAIDs including selective COX-2 inhibitors.

Selective inhibition of COX-2 was once thought to be a way to reduce the incidence of gastric ulceration. ${ }^{28,32,33}$ Chronic use of these products, however, was shown to lead to a high incidence of ulceration. ${ }^{34}$ Understanding AA metabolism and the importance of balancing COX-1 and COX-2 enzyme activity has become central in prescribing decisions for traditional NSAIDs, selective inhibitors, or recommending alternative therapies. Cyclooxygenases represent only one set of metabolic pathways to consider. Other inducible factors, such as cytokines and alternate inflammatory pathways like 5-LOX, also contribute to the pathogenesis of OA.

Evidence suggests that significant mechanical strain in a joint results in up-regulation of the pro-inflammatory cytokines TNF $\alpha$ and IL- $1 \beta .{ }^{35,36} \mathrm{IL}-1 \beta$ then triggers production of reactive oxygen species (ROS) that induce expression of the pro-inflammatory transcription factor, nuclear factor kappa-B $(\mathrm{NF}-\mathrm{\kappa B}),{ }^{37,38}$ triggering an inflammatory cascade that, in turn, leads to up-regulation of COX-2 $2^{39}$ and chondrodestructive metalloproteinases. $.^{40} \mathrm{NF}-\mathrm{\kappa B}$ is an important transcription factor complex that regulates the expression of more than 
400 genes involved in immune function and inflammation. ${ }^{41,42}$ In an inactivated state, $\mathrm{NF}-\kappa \mathrm{B}$ is bound by the inhibitory protein I $\kappa \mathrm{B} \alpha$ within the cytosol. ${ }^{43}$ Upon activation by extracellular signals and ubiquitination of $\mathrm{I} \kappa \mathrm{B} \alpha$, free NF- $\mathrm{B}$ rapidly translocates to the nucleus where it activates the transcription of target genes including those encoding pro-inflammatory cytokines, adhesion molecules, chemokines, and inducible enzymes such as COX-2, 5-LOX, and inducible nitric oxide synthase (iNOS). ${ }^{44}$ This activation and induction of inflammatory factors leads directly to increases in tissue destruction in OA and other chronic diseases. Modulation of NF-kB is a key element in managing the metabolic aspects of joint deterioration.

In the past decade, several agents that inhibit both COX and 5-LOX pathways have entered clinical development. Many of these so-called "dual inhibitors" do not cause some of the side effects that are typical of NSAIDs or COX-2 inhibitors, including the cardiovascular, renal, and gastrointestinal damage and discomfort caused by traditional NSAIDs. ${ }^{45}$ For example, it has been suggested that NSAID induced gastric inflammation is largely due to metabolites of 5-LOX, particularly $\mathrm{LTB}_{4} \cdot{ }^{46} \mathrm{Leu}-$ kotrienes, and especially $\mathrm{LTB}_{4}$, are found in high concentrations in the walls of NSAID induced gastric ulcers and represent the primary AA metabolites within the gastric mucosa following prostanoid inhibition. Their presence suggests a shunt of AA metabolism toward leukotriene production as a result of COX inhibition. ${ }^{47}$ These compounds are highly leukoattractive and contribute to a significant amount of the NSAID induced gastric epithelial injury. ${ }^{48}$ Additional evidence for 5-LOX shunting caused by NSAIDs can be seen in the production of leukotrienes in patients on aspirin or similar cross reacting NSAIDs who develop asthmatic symptoms, ${ }^{49,50}$ in animal models of NSAID induced cardiac ischemia, ${ }^{51}$ and human OA synovial explants exposed to NSAIDs. ${ }^{52}$ Taken together, these characteristics suggest that there may be distinct advantages to dual inhibition of COX and 5-LOX over COX-1 and/or COX-2 alone with regard to both increased efficacy and improved safety profile.

\section{Role of nutrition in OA}

Epidemiological studies have shown that Asian and Mediterranean countries have a substantially lower incidence of knee OA suggesting an etiologic role for nutritional factors..$^{15}$ Excess consumption of omega- 6 fatty acids may account, in part, for this difference. Arachidonic acid is derived from the dietary intake of AA itself and essential fatty acids (EFA), linoleic acid, and $\alpha$-linolenic acid followed by sequential desaturation and elongation. ${ }^{53}$ Fatty acid imbalances are commonly seen in patients with chronic inflammatory conditions such as arthritis. Osteoarthritic joints typically show increased levels of lipid and AA accumulation which correlate with histological severity. ${ }^{54,55}$ Fatty acid levels in subchondral bone have been shown to be $50 \%-90 \%$ higher in OA patients compared to controls. ${ }^{56}$ Dietary lipids have also been shown to modify the fatty acid composition of cartilage. ${ }^{57}$ In addition, clinical studies have shown a strong linkage between metabolic defects in EFA metabolism or an overabundance of fatty acids that lead to OA. ${ }^{58}$

Flavonoids and other dietary antioxidants have been shown to slow the progression of $\mathrm{OA},{ }^{59}$ possibly by managing the production of inflammatory oxidized lipids, enzymatically formed AA metabolites and reduction of transcriptional factors which induce other inflammatory components. This metabolic modulation may restore a more normal balance of fatty acid metabolism in the presence of excess omega- 6 and AA dietary intake. Medical foods are ideally positioned to provide the clinical dietary management of chronic diseases like OA.

\section{Regulatory considerations}

Unlike drugs, medical foods are not developed under Investigational New Drug (IND) procedures or licensed under New Drug Application (NDA) requirements, but are subject to a specific set of governing regulations of their own. They are not "approved" by the FDA in the same manner as drugs, but are required to support all claims with good laboratory and clinical science. The category of Medical Foods was created in an addendum to the Orphan Drug Act of 1988. Prior to this they were regulated as drugs. The definition of a medical food was restated in the FDA's Final Rule on Mandatory Nutritional Labeling, January, 1993. Specifically, a product classified as a medical food must meet the following requirements, among others:

- It is a specially formulated and processed product (as opposed to a naturally occurring foodstuff used in its natural state).

- It must be consumed or administered enterally, either by ingestion or intragastric tube.

- It provides nutritional support specifically modified for the management of the unique nutrient needs that result from the specific disease or condition, as determined by medical evaluation.

- The nutritional need could not reasonably be supplied by dietary alteration alone.

- It is intended to be used under medical supervision (ie, by prescription).

- It is intended only for a subject receiving active and ongoing medical supervision wherein the subject requires medical care on a recurring basis, ie, medical foods are intended for a diseased population.

- It is composed of ingredients designated as generally recognized as safe (GRAS). For an ingredient to achieve 
GRAS status requires not only a technical demonstration of non-toxicity, but also an agreement of that safety after extensive peer review by an independent panel of experts in the field.

- It is based on recognized scientific principles.

\section{Medical foods vs dietary supplements}

The terms medical food and dietary supplement are not interchangeable. ${ }^{60}$ These are discrete regulatory classifications with specific statutory definitions for each. The use of medical foods, even though they are composed of GRAS ingredients, must be prescribed and monitored by a physician while supplements are available over the counter. Moreover, supplements cannot make disease claims as their intended use is to preserve health in healthy people while medical foods, because they are intended for use in a diseased population, must make disease claims.

\section{Flavocoxid}

Flavocoxid is classified as a medical food under US FDA regulations. The product is a proprietary blend of processed and standardized free-B-ring flavonoids (baicalin; Figure 2a) derived from the plant Scutellaria baicalensis and flavans (catechin; Figure 2b) derived from the plant Acacia catechu.

As outlined in the following sections, flavonoids, in this specific combination, demonstrate a high degree of inhibition for COX-1, COX-2, and 5-LOX as well as other anti-inflammatory properties stemming from a strong antioxidant capacity. Flavocoxid's ingredient specification and analytical methods follow prescription drug standards and the product is manufactured according to current FDA Good Manufacturing Practices (GMP) for prescription drugs. This is a higher standard than that required for over the counter drugs, foods, or dietary supplements.

\section{In vitro studies: anti-inflammatory properties}

To isolate the components of flavocoxid (also known by the laboratory code UP446 in earlier publications), in vitro high throughput and enzyme assays, using recombinant ovine isozymes, were used to measure peroxidase (POX) inhibition for both COX-1 and COX-2 of more than 2,500 plant extracts. ${ }^{61}$ For isolation and characterization of the 5-LOX inhibition activity, a plant-based 5-LOX enzyme was used since no human isoform was commercially available at the time. Candidate extracts were then further purified by high performance liquid chromatography (HPLC) to single chemical entities, in this case, baicalein and catechin, to isolate
A. Baicalin (MW = 446.37)

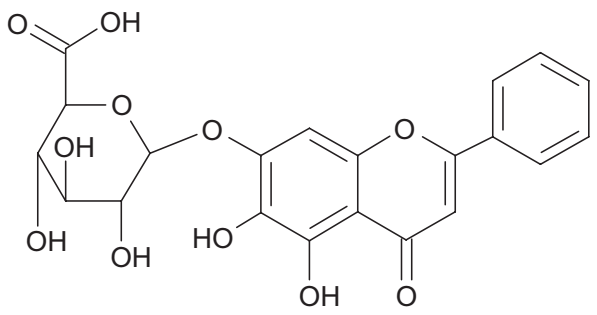

B. Catechin $(\mathrm{MW}=290.27)$

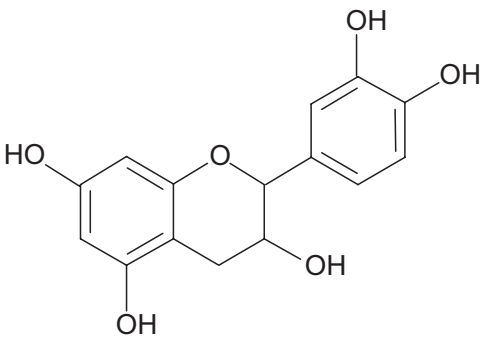

Figure 2 Molecular structure of baicalin and catechin components of flavocoxid.

the corresponding POX, for COX-1 and COX-2, and 5-LOX inhibitory activities. ${ }^{59}$ Both enzymatic inhibition studies as well as cell-based assays were then utilized in vitro to examine the anti-inflammatory properties and mechanism of action of flavocoxid. To determine the IC50 dose levels in vitro for POX activity inhibition within the COX enzymes, flavocoxid was titrated into the purified enzyme system. One could argue that inhibition of the POX activity is not a direct measure of COX inhibition since NSAIDs inhibit the COX activity of COX-1 and COX-2, rather than the POX activity. The COX activity of both enzymes first oxygenates AA to produce $\mathrm{PGG}_{2}$, which then is converted to $\mathrm{PGH}_{2}$ by the POX activity followed by cell-specific synthetase conversion to individual PGs or thromboxanes (TXs). ${ }^{62}$ Since the two enzyme activities are coupled and required to produce the end-product, inhibition of one or both activities reflects downregulation of overall COX enzyme activity and end product generation. ${ }^{63}$

In the POX inhibition assay to determine the half maximal inhibitory concentration $\left(\mathrm{IC}_{50}\right)$ for $\mathrm{COX}-1$ and $\mathrm{COX}-2$, there was an exponential rise in inhibitory activity with flavocoxid doses between $10-100 \mu \mathrm{g} / \mathrm{mL}$ with nearly $100 \%$ inhibition being achieved at the higher dose levels. The $\mathrm{IC}_{50}$ for both COX-1 POX and COX-2 POX inhibition was $15 \mu \mathrm{g} / \mathrm{mL} .{ }^{64}$ Further work is currently underway to elucidate the specific inhibitory capacity of flavocoxid for the COX moiety within both COX-1 and COX-2 using a more traditional oxygen consumption assay. ${ }^{65,66}$ Although the complete mechanism of action for 
inhibition of the COX enzymes has not been elucidated, the 5-LOX inhibitory activity has been determined.

The 5-LOX $\mathrm{IC}_{50}$ was also determined by titration of flavocoxid into this purified enzyme system using a commercial 5-LOX screening kit. ${ }^{64}$ Again, there was a steep rise in inhibitory activity between $10-100 \mu \mathrm{g} / \mathrm{mL}$ concentrations of flavocoxid with an $\mathrm{IC}_{50}$ of $25 \mu \mathrm{g} / \mathrm{mL}$ for 5 -LOX inhibition. Enzyme assays represent a useful tool for elucidating mechanism of action, but measurement of the end products is also necessary. Cell assay are the principle tool which has been used to verify the findings from the enzyme assays.

Burnett et al found that $\mathrm{PGE}_{2}$ levels from COX-2 were reduced as flavocoxid was titrated into human osteosarcoma (HOSC) cultures. ${ }^{64}$ Celecoxib was a much better COX-2 inhibitor in this assay, perhaps reflecting its specific COX inhibitory activity compared to the POX inhibition of flavocoxid. Flavocoxid also inhibited the production of LTB $_{4}$ in THP-1 monocyte cells when titrated into culture. ${ }^{64}$ In another set of cell assays performed in rat peritoneal macrophages induced to an inflammatory phenotype with lipolysaccharide (LPS), flavocoxid significantly blunted $\mathrm{NF}-\kappa \mathrm{B}$ activation and restored $\mathrm{I} \kappa \mathrm{B} \alpha$ expression, the cytoplasmic modulatory factor for $\mathrm{NF}-\kappa \mathrm{B} .{ }^{67}$ As a consequence of NF- $\kappa \mathrm{B}$ modulation, COX-2, 5-LOX, iNOS, and TNF $\alpha$ protein expression was reduced when flavocoxid was titrated into culture. The metabolites of COX-2, 5-LOX, and iNOS, $\mathrm{PGE}_{2}, \mathrm{LTB}_{4}$, and nitrate were similarly reduced. Finally, flavocoxid, acting as a direct antioxidant, also decreased the formation of malondialdehyde from AA. ${ }^{67}$ It is this antioxidant capacity that is most likely responsible for the modulation of NF- $\kappa \mathrm{B}$ activation. ${ }^{25}$ Further work on the specific antioxidant capacity as well as genomic mechanisms involved in the modulation of inducible inflammatory factors is under way.

\section{Mutagenicity}

To understand the toxicity profile of flavocoxid, a number of in vitro assays including cytotoxicity, ${ }^{68} \mathrm{AMES}$ mutagenesis assay, ${ }^{69,70}$ and human liver microsome CYP450 drug interaction assays ${ }^{71}$ were performed. In a cytotoxicity study in THP-1 monocytes, flavocoxid, aspirin, and ibuprofen caused a 5\%-10\% cell death while indomethacin and celecoxib resulted in $80 \%-100 \%$ cell mortality when titrated into culture between $50-100 \mu \mathrm{g} / \mathrm{mL} .^{72}$ In contrast, flavocoxid displayed low cytotoxicity at the highest concentration tested, $100 \mu \mathrm{g} / \mathrm{mL}$. In addition, flavocoxid caused no mutagenicity as judged by a reduction of the Salmonella typhimurium bacterial background lawn or decrease in the number of spontaneous revertants at any dose level and in any of the five different strains tested. In the presence of liver enzymes for metabolic activation, flavocoxid did not increase the incidence of revertants, but was slightly cytotoxic in three of five strains of S. typhimurium.

\section{Drug interactions}

Compounds that inhibit the CYP450 isoenzymes by $50 \%$, or more, may significantly affect metabolism of one or more drugs and should be further characterized by determination of an $\mathrm{IC}_{50}$ and a pharmacokinetic study in humans to assess the maximum safe in vivo exposure. Flavocoxid at a concentration of approximately $10 \mu \mathrm{M}$ showed moderate inhibition (23\%) of CYP1A2 and only a slight inhibition of CYP3A4 (11\%), ${ }^{72}$ the principal metabolizing enzyme of $50 \%$ of all pharmaceutical drugs. ${ }^{73,74}$ Similar inhibition findings were noted for CYP2C9, CYP2C19, and CYP2D6 $(11 \%-16 \%)$. Because flavocoxid did not inhibit any one of the five principle drug metabolizing enzymes to $50 \%$, it does not have major drug interactions and should be safe to take with most medications.

These accumulated in vitro studies suggest that flavocoxid acts via multiple inflammatory pathways on the enzymatic, antioxidant, gene, and protein expression levels and may be safe in patients due to low cytotoxicity, lack of a mutagenic effect, and absence of major CYP450 drug metabolizing inhibitions. The proof of any good therapeutic effect for a specific condition or disease, however, is the effect seen in vivo. Therefore, flavocoxid has been tested in both preclinical and clinical studies to evaluate safety and efficacy.

\section{Preclinical: safety studies}

Acute (14 days) and subchronic (91 days) toxicity studies were performed $^{72}$ in 5- to 6-week old male and female imprinting control region (ICR) mice by feeding 250, 1,250, 2,500, and $10,000 \mathrm{mg}$ daily human equivalent dosages of flavocoxid. ${ }^{75}$ No differences in weight, gross pathology, hematology, or blood chemistry and histology of liver, kidney, duodenum, and stomach tissues were found in the treated vs untreated animals. A similar study was performed in 6- and 18-month old F344 male rats fed 0 or $34 \mathrm{mg} / \mathrm{kg} /$ day of flavocoxid for 9-10-weeks and, again, no abnormalities in weight, gross pathology, blood counts, or chemistry or histological examinations were found..$^{72}$ The lack of tissue damage in the duodenum or stomach tissues is particularly significant in rats since this species is sensitive to the adverse effects of traditional NSAIDs, forming gastrointestinal lesions when dosed with as little ibuprofen as $2 \mathrm{mg} / \mathrm{kg}$ /day, equivalent to approximately $140 \mathrm{mg}$ /day in humans.$^{76}$ Other flavonoids have 
also been shown to either be gastric protective or have been used for the treatment of gastric ulcerations. ${ }^{77}$

\section{Anti-inflammatory efficacy models}

Anti-inflammatory efficacy was determined initially in animals by using AA-based topical ear and intra-articular ankle swelling assays. ${ }^{64}$ Arachidonic acid has been shown to induce the production of prostaglandins and leukotrienes when applied to various tissues. ${ }^{78}$ The presence of both COX and LOX inhibitors has also been shown to abate swelling responses in AA-induced inflammatory models. ${ }^{79}$ Flavocoxid (50, 100 or $200 \mathrm{mg} / \mathrm{kg}$ ), administered by oral gavage to 4-5-week old ICR mice (Harlan Labs) 12 hours before AA application to ears or injection into ankles, blocked AA-induced inflammatory effects. ${ }^{64}$ Indomethacin $(50 \mathrm{mg} / \mathrm{kg}$ ) gave a comparable response in the same assay. In the intra-articular AA model, there was a corresponding restoration of function as determined by comparing the flavocoxid treated and nontreated animals' abilities to run on a rotating rod. ${ }^{64}$ More direct models of measuring flavocoxid's efficacy have also been used in animals with OA.

A formulation of flavocoxid specifically for canines was compared to a glucosamine hydrochloride/chondroitin sulfate/ manganese ascorbate formulation in a multisite, double-blind, randomized, direct-comparator trial in dogs with OA weighing at least $15 \mathrm{lbs} .{ }^{80}$ The flavocoxid formulation $(\mathrm{n}=33)$ showed statistically significant improvement in discomfort over the combination formulation of glucosamine hydrochloride/ chondroitin sulfate/manganese ascorbate formulation $(n=36)$ using veterinarian and owner visual analog scale (VAS) assessments. At both the interim (28 days) and final analysis (56 days), the flavocoxid formulation was more than twice as effective as the glucosamine hydrochloride/chondroitin sulfate/manganese ascorbate formulation at managing discomfort in this canine population. The VAS for discomfort was shown to be statistically separable at 56 days for flavocoxid formulation over the glucosamine hydrochloride/chondroitin sulfate/manganese ascorbate formulation. Adverse events were generally mild and equivalent in both groups.

\section{Clinical studies: pharmacokinetic study}

Baicalin and other flavonoids are partially water-soluble molecules and are absorbed intact to varying degrees in the gastrointestinal tract following oral administration via a glucose transporter system such as GLUT-4. The vast majority of the glycosidic form resists digestion by acid in the stomach and arrives intact in the duodenum. ${ }^{81}$ The tissue and species-specific glycosidases, present in the gastrointestinal microflora and brush border membrane, convert the flavonoid glycosides into aglycones such as baicalein. ${ }^{82-84} \mathrm{~A}$ small percentage $(<10 \%)$ of the aglycone baicalein is restored to baicalin in the liver following absorption, and circulates in the body primarily bound to plasma proteins. ${ }^{85,86}$ Aglycones and other flavonoids are often further metabolized by C-ring fission, resulting in the formation of two phenolic products: a methylation and a sulfation product. ${ }^{87,88}$ The proportion of each modification seems to vary according to the type and amount of flavonoid ingested, species, sex, and food deprivation with glucuronidation favored over sulfation and sulfation favored over methylation. ${ }^{89,90}$ The conversion of baicalin to baicalein is highly variable in each individual depending on the concentration and type of intestinal flora in the small intestine. ${ }^{91}$ Excretion occurs primarily via the biliary system.

Catechin (also known as (+)-catechin) is readily absorbed in the small intestine and does not undergo any predigestion. ${ }^{92}$ The absorption of catechin from the gastrointestinal tract is rapid and immediately followed by a conjugation step in the intestinal mucosa to produce a methylated metabolite. ${ }^{88}$ The glucuronidated catechins enter the portal vein and are either sulfated in the liver, or sulfated and methylated in the kidneys. Excretion occurs in the bile and urine. ${ }^{93}$ Animal studies have shown that the majority of catechin in excreted in the urine and in the breath, as respired carbon dioxide. ${ }^{94}$ The results of this study, in which volunteers were administered $(4 \times)$ $500 \mathrm{mg}$ of $(+)$-catechin, indicated that more than half of the original dose was absorbed as the intact flavanol from the human intestine. ${ }^{95}$ The half-life for catechins has been reported to range from 2-3 hours ${ }^{96}$ and plasma levels are observed to peak $\sim 3$ hours after administration in humans, with levels still detectable 120 hours later, probably due to reabsorption and enterohepatic circulation. ${ }^{95}$ Overall, the hepatic extraction of orally administered catechin is rapid and efficient, with relatively low levels of the unchanged compound present in the plasma. Since the relative pharmacokinetic profile of catechin is known, and it exists as a minority of the composition in flavocoxid, a pharmacokinetic study was undertaken with a single dose of flavocoxid in fasted subjects to determine the baicalin absorption and excretion profile.

Ten fasted human subjects received $500 \mathrm{mg}$ of flavocoxid under controlled conditions. Plasma samples were collected at $1 / 2,1,2,4,8$, and 24 hours and again on day 7 post-dose. After digestion of the plasma samples with $\beta$-glucuronidase and sulfatase, serum baicalein levels were measured and pharmacological parameters including area under curve (AUC), maximum concentration $\left(\mathrm{C}_{\max }\right)$, time to reach $\mathrm{C}_{\max }$ 
$\left(\mathrm{T}_{\max }\right)$, and half-life $\left(\mathrm{T}_{1 / 2}\right)$ determined. Although considerable individual variation was noted in the data, the average AUC was $7,007 \mu \mathrm{g} / \mathrm{mL} /$ hour, $\mathrm{C}_{\max }$ was $0.93 \mu \mathrm{g} / \mathrm{mL}, \mathrm{T}_{\max }$ was 5.8 hours, and the $\mathrm{T}_{1 / 2}$ was approximately $11-12$ hours. The average pharmacokinetic profile over the first 24 hours is shown in Figure 3.

This study represents a single dose pharmacokinetic profile. A steady-state pharmacokinetic study may be needed to elucidate the absorption and excretion profile of baicalin and catechin in combination. In addition, not all of the metabolite input can be accounted for when administering flavonoids orally, so further work may be needed to find the reservoirs in which these molecules reside.

Baicalein is primarily converted to 6-O-beta-glucopyranuronoside (M1), 6-O-beta-methyl-baicalein 7-O-betaglucopyranuronoside (M2), baicalein 7-O-glucopyranuronoside (M3), 6-O-beta-glucopyranuronosyl-baicalein 7-O-sulfate (M4), and baicalein 6,7-di-O-beta-glucopyranuronoside (M5). ${ }^{97}$ The M4 and M5 metabolites are the vast majority found in biliary secretion at about $40 \%-50 \%$ (of the $10 \%$ that reaches the liver) of the total input over 30 hours in a rat study whereas renal secretion of these metabolites accounts for under $10 \%{ }^{98}$ Therefore, approximately $40 \%$ of all input flavonoid cannot be accounted for using these analyses. Some may show up in the feces, however, due to extensive degradation of baicalein by colonic microflora, exact quantification is difficult. ${ }^{99}$ There may also be other reservoirs that account for missing flavonoids in these studies.

Several recent studies have demonstrated that the bioavailability of flavonoids may be much greater than initially believed. ${ }^{100}$ It has been shown that flavonoid molecules bound by serum albumin are taken up by red blood cells (RBCs), which essentially act as a reservoir for these

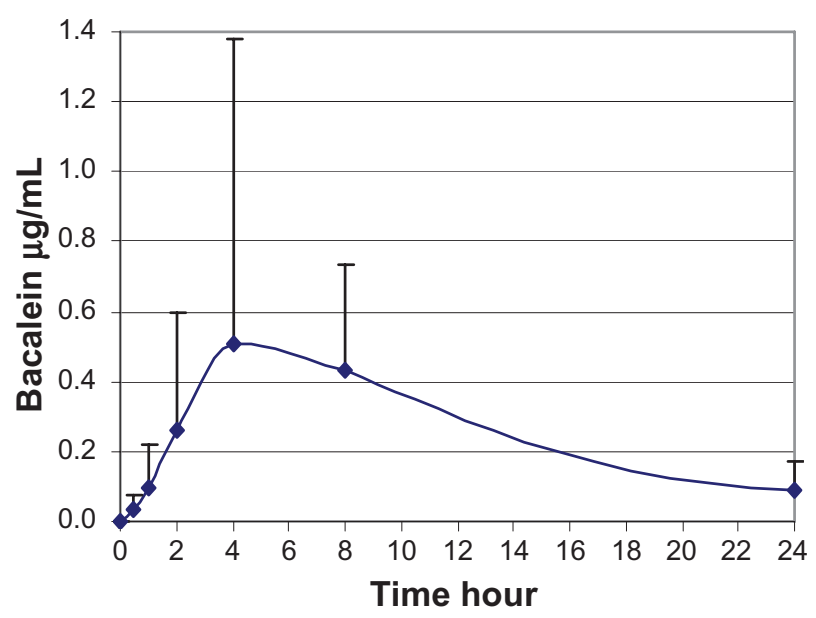

Figure 3 Pharmacokinetic profile of uptake and clearance of baicalein, the aglycone metabolite of baicalin. molecules. ${ }^{101,102}$ Flavonoids are subsequently released from the RBCs when the albumin molecule becomes "desaturated" by the release of bound endogenous or exogenous substances. Therefore, it is reasonable to assume that the concentration of circulating flavonoids such as baicalein and catechin in human plasma is even greater when the amount associated with RBCs is considered. Furthermore, the relatively slow elimination half-life of baicalein of $\sim 6$ hours can be explained by its high affinity for albumin. About $90 \%$ of baicalin ${ }^{103}$ and $45 \%$ of catechin ${ }^{104}$ are bound by serum albumin. Alternatively, the slow release from $\mathrm{RBC}$ reservoirs may also explain the observed half-life of baicalein in our study. Other health factors may also affect flavocoxid bioavailability.

Two animal studies have suggested that antibiotics can reduce the level of glucoside processing microflora in the small intestine, thereby decreasing the conversion of baicalin to baicalein, and ultimately the uptake of baicalein into the blood. ${ }^{105,106}$ Therefore, the efficacy of flavocoxid may be affected while a patient is on a short course of antibiotics although this has not been confirmed in human studies.

\section{Clinical studies}

The flavocoxid composition has been studied in several controlled clinical trials. In an initial safety study, Burnett et al administered flavocoxid $250 \mathrm{mg}$ or placebo every day to healthy volunteers $(n=80)$ for 5 weeks. ${ }^{72}$ Subjects were sex matched and recruited from ages 40 to 75 years. Subjects taking NSAIDs underwent a 2-week washout period before the baseline visit. Physical activity was not restricted and the subjects were not given any advice pertaining to diet. Safety was measured by the incidence of treatment-emergent adverse events (AEs) and laboratory abnormalities. Symptomatic AEs were few, mild, and comparable in treated and placebo groups. No mean values for plasma biochemistry of either group fell outside of the clinically acceptable ranges.

A 3-month safety study was performed in 59 OA subjects given flavocoxid $250 \mathrm{mg}$ bid or placebo. ${ }^{60}$ There were no differences in AEs or blood chemistries except for an apparent reduction in upper respiratory related AEs in the flavocoxid group (flavocoxid 4 vs placebo 17; $P=0.0001$ ). Flavonoids, including catechins and flavonols, such as baicalin, have been studied for their antimicrobial activity and potential usefulness against infectious diseases in humans. ${ }^{107-109}$ Baicalin, purified from $S$. baicalensis, has been traditionally used as an anti-inflammatory and anti-allergic agent in the treatment of many inflammatory diseases ranging from bronchitis to atopic dermatitis. ${ }^{110}$ Gargling tea catechin extracts has been shown to significantly reduce the incidence of influenza 
infection in elderly nursing home residents compared to a control group receiving placebo. ${ }^{111}$ This property of flavocoxid will be explored in more detail in future studies.

A 1-month randomized, multicenter, pilot efficacy study comparing flavocoxid $500 \mathrm{mg}$ bid with naproxen $500 \mathrm{mg}$ bid enrolled 103 subjects of whom 101 completed the study. ${ }^{112}$ In this short-term study, flavocoxid and naproxen were statistically identical with regard to both efficacy ( $>80 \%$ response, overall) (Figure 4 ) and safety ( $21 \%$ AEs, none serious). ${ }^{112}$

A 3-month randomized, double-blind, multicenter study comparing flavocoxid $500 \mathrm{mg}$ bid $(\mathrm{n}=106)$ with naproxen $500 \mathrm{mg}$ bid $(\mathrm{n}=114)$ has recently been completed (submitted for publication). There was no significant difference in efficacy measured by multiple conventional parameters including WOMAC scales, timed walk, and multiple VAS scales when the entire intent to treat population is considered. There was a statistically significant reduction in upper gastrointestinal AEs and edema in the flavocoxid group.

Flavocoxid has been marketed under the brand name Limbrel since May, 2004. Despite the vagaries of voluntary post-marketing reporting, there has been a notable lack of renal, cardiovascular, and upper gastrointestinal AEs. With more than 150,000 new prescriptions filled, the most common complaints are referable to lower gastroinstestinal distress, primarily diarrhea, and flatulence. This is consistent with formal clinical trials where the incidence of these complaints has been about $5 \%$, but has not resulted in any study subject drop outs. In clinical trials, elevated liver function tests have been noted, but have not been significantly different in frequency from naproxen. Occasional reports of allergic reactions such as rashes or hives $(<0.2 \%)$ and rare cases $(n=6)$ of hypersensitivity pneumonitis requiring treatment with glucocorticoids and oxygen have been reported.

A multicenter, in-market rheumatological study in over 1,000 patients given $500 \mathrm{mg}$ bid assessing response rate, AEs, gastrointestinal tolerability, and reduction in gastroprotective use has also been performed. ${ }^{113}$ Initial evaluation of results demonstrated that flavocoxid is well-tolerated in NSAID sensitive individuals, reduces the use of gastroprotectives, and has a high response rate. In addition, an anticoagulant study showing absence of flavocoxid effect on aspirin-induced blood thinning in an animal model, a platelet function study in patients taking $500 \mathrm{mg}$ bid flavocoxid for 14 days $(\mathrm{n}=10)$ showing no effect on bleed times or platelet aggregation and an open-label study in rheumatological practices of flavocoxid administered for 2 weeks at either 250 or $500 \mathrm{mg}$ bid in warfarinized patients demonstrating no effect on international normalized ratio $(I N R)(n=59)$ have been completed and

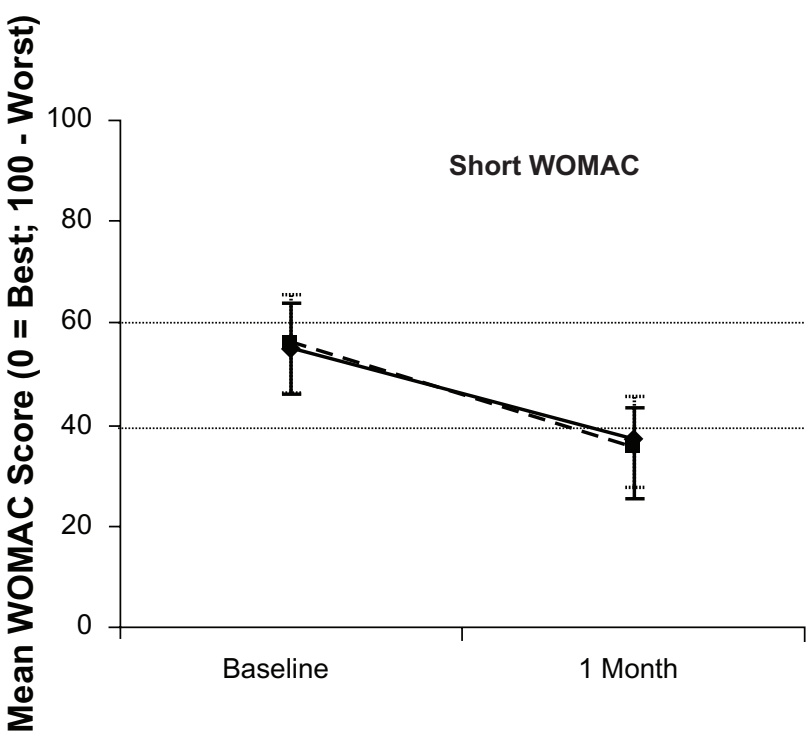

Figure 4 Improvements in efficacy with flavocoxid. Levy et al (2009) showed no statistically significant differences in WOMAC scores between the flavocoxid and naproxen arms during a 4-week clinical trial. The means and \pm SEM are shown for this efficacy measurement. Differences between groups were not significant $(P>0.2)$. Decreasing trends indicated improvement $(P \leq 0.001)$. indicates flavocoxid, $500 \mathrm{mg}$ bid $\mathbf{~ i n d i c a t e s ~ n a p r o x e n ~} 500 \mathrm{mg}$ bid.

have been submitted for publication. These peer-reviewed trials will provide a better clinical profile for flavocoxid to aid clinicians in their prescribing decisions.

\section{Conclusion}

The goal of a metabolic therapy for $\mathrm{OA}$ is to reduce oxidative stress and restore a more normal balance of fatty acid metabolism in the presence of excess omega- 6 and AA dietary intake. Flavonoids and dietary antioxidants, such as those contained in flavocoxid, have been shown to slow the progression of $\mathrm{OA}^{59}$ possibly by managing the production of inflammatory oxidized lipids, enzymatically formed AA metabolites, and reduction of transcriptional factors which induce other inflammatory components. Further testing of the mechanism of action of flavocoxid is underway as well as testing to determine if flavocoxid is cartilage protective and/or restorative.

Flavocoxid (Limbrel), a prescription medical food based on a proprietary formula of purified flavonoid molecules, represents a new class of anti-inflammatory agents compared to traditional NSAIDs or COX-2 selective inhibitors. Specifically, flavocoxid acts as a balanced peroxidase inhibitor of COX-1 and COX-2 with additional 5-LOX inhibitory activity to avoid AA metabolic shunting toward leukotriene production. In addition, flavocoxid works via antioxidant mechanisms to downregulate the inducible production of inflammatory pathways, mRNA and proteins, and as a direct antioxidant to presumably decrease cartilage damage. Flavocoxid has also 
been shown in two pilot safety trials to be safe vs placebo and in two efficacy studies to be equivalent to naproxen. As such, flavocoxid represents the first broad-based, flavonoid antiinflammatory that has been well-studied for its mechanism of action, drug interactions, mutagenesis, and preclinical and clinical safety and efficacy to appear on the market. It represents a new option for the clinical dietary management of the metabolic aspects of OA.

\section{Disclosure}

The authors are employed by Primus Pharmaceuticals, Inc. who have licensed a compositional patent on flavocoxid (Limbrel) and provided financial sponsorship for the associated clinical trials.

\section{References}

1. Liu Y, Wang MW. Botanical drugs: challenges and opportunities: contribution to Linnaeus Memorial Symposium 2007. Life Sci. 2008;82(9-10):445-449.

2. Farnsworth NR. The role of ethnopharmacology in drug development [discussion]. Ciba Found Symp. 1990;154:2-11; discussion 11-21.

3. Fabricant DS, Farnsworth NR. The value of plants used in traditional medicine for drug discovery. Environ Health Perspect. 2001;109 Suppl 1:69-75.

4. Adegbehingbe OO, Adesanya SA, Idowu TO, Okimi OC, Oyelami OA, Iwalewa EO. Clinical effects of Garcinia kola in knee osteoarthritis. J Orthop Surg Res. 2008;3:34.

5. Farid R, Mirfeizi Z, Mirheidari M, et al. Pycnogenol supplementation reduces pain and stiffness and improves physical function in adults with knee osteoarthritis. Nutr Res. 2007;27:692-697.

6. Cisar P, Jany R, Waczulikova I, et al. Effect of pine bark extract (Pycnogenol) on symptoms of knee osteoarthritis. Phytother Res. 2008;22(8):1087-1092.

7. Belcaro G, Cesarone MR, Errichi S, et al. Treatment of osteoarthritis with Pycnogenol. The SVOS (San Valentino Osteo-arthrosis Study). Evaluation of signs, symptoms, physical performance, and vascular aspects. Phytother Res. 2008;22(4):518-523.

8. Lozada CJ, Altman RD. Management of osteoarthritis. In: Koopman Wj, ed. Arthritis and Related Conditions. Philadelphia, PA: Lippincott, Williams, and Wilkins; 2001:2246.

9. Felson DT, Naimark A, Anderson J, Kazis L, Castelli W, Meenan RF. The prevalence of knee osteoarthritis in the elderly. The Framingham Osteoarthritis Study. Arthritis Rheum. 1987;30(8):914-918.

10. Claessens AA, Schouten JS, van den Ouweland FA, Valkenburg HA. Do clinical findings associate with radiographic osteoarthritis of the knee? Ann Rheum Dis. 1990;49(10):771-774.

11. Peat G, McCarney R, Croft P. Knee pain and osteoarthritis in older adults: a review of community burden and current use of primary health care. Ann Rheum Dis. 2001;60(2):91-97.

12. Felson DT. Clinical practice. Osteoarthritis of the knee. NEngl J Med. 2006;354(8):841-848.

13. Bolin J, Helmick CG, Sacks JJ, Langmaid G; Center for Chronic Disease Prevention and Health Promotion. Prevalence of self-reported arthritis or chronic joint symptoms among adults - United States, 2001. MMWR Morbid Mortal Wkly Rep. 2002;51(42):948-950 .

14. Pleis JR, Lethbridge-Cejku M. Summary health statistics for US adults: National Health Interview Survey, 2006. Vital Health Stat 10. 2007(235):1-153.

15. Woolf AD, Pfleger B. Burden of major musculoskeletal conditions. Bull World Health Organ. 2003;81(9):646-656.
16. Odding E, Valkenburg HA, Algra D, Vandenouweland FA, Grobbee DE, Hofman A. Associations of radiological osteoarthritis of the hip and knee with locomotor disability in the Rotterdam Study. Ann Rheum Dis. 1998;57(4):203-208.

17. White AG, Birnbaum HG, Janagap C, Buteau S, Schein J. Direct and indirect costs of pain therapy for osteoarthritis in an insured population in the United States. J Occup Environ Med. 2008;50(9): 998-1005.

18. De Filippis L, Gulli S, Caliri A, et al. [Epidemiology and risk factors in osteoarthritis: literature review data from "OASIS" study]. Reumatismo. 2004;56(3):169-184. Italian.

19. Rabenda V, Manette C, Lemmens R, Mariani AM, Struvay N, Reginster JY. Direct and indirect costs attributable to osteoarthritis in active subjects. $J$ Rheumatol. 2006;33(6):1152-1158.

20. Gabriel SE, Crowson CS, Campion ME, O'Fallon WM. Direct medical costs unique to people with arthritis. J Rheumatol. 1997; 24(4):719-725.

21. Van Saase JL, van Romunde LK, Cats A, Vandenbroucke JP, Valkenburg HA. Epidemiology of osteoarthritis: Zoetermeer survey. Comparison of radiological osteoarthritis in a Dutch population with that in 10 other populations. Ann Rheum Dis. 1989;48(4):271-280.

22. Reginster JY. The prevalence and burden of arthritis. Rheumatology (Oxford). 2002;41 Suppl 1:3-6.

23. McAlindon TE, Snow S, Cooper C, Dieppe PA. Radiographic patterns of osteoarthritis of the knee joint in the community: the importance of the patellofemoral joint. Ann Rheum Dis. 1992; 51(7):844-849.

24. Dannhardt G, Kiefer W. Cyclooxygenase inhibitors - current status and future prospects. Eur J Med Chem. 2001;36(2):109-126.

25. Burnett BP, Levy R, Cole BJ. Metabolic mechanisms in the pathogenesis of osteoarthritis: a review. J Knee Surg. 2006;19(3):191-197.

26. Grosser T, Fries S, FitzGerald GA. Biological basis for the cardiovascular consequences of COX-2 inhibition: therapeutic challenges and opportunities. J Clin Invest. 2006;116(1):4-15.

27. Warner TD, Mitchell JA. Cyclooxygenases: new forms, new inhibitors, and lessons from the clinic. FASEB J. 2004;18(7):790-804.

28. Bombardier C, Laine L, Reicin A, et al. Comparison of upper gastrointestinal toxicity of rofecoxib and naproxen in patients with rheumatoid arthritis. VIGOR Study Group. $N$ Engl J Med. 2000; 343(21):1520-1528.

29. Solomon DH, Schneeweiss S, Glynn RJ, et al. Relationship between selective cyclooxygenase-2 inhibitors and acute myocardial infarction in older adults. Circulation. 2004;109(17):2068-2073.

30. Nussmeier NA, Whelton AA, Brown MT, et al. Complications of the COX-2 inhibitors parecoxib and valdecoxib after cardiac surgery. N Engl J Med. 2005;352(11):1081-1091.

31. Solomon SD, McMurray JJ, Pfeffer MA, et al. Cardiovascular risk associated with celecoxib in a clinical trial for colorectal adenoma prevention. N Engl J Med. 2005;352(11):1071-1080.

32. Silverstein FE, Faich G, Goldstein JL, et al. Gastrointestinal toxicity with celecoxib vs nonsteroidal anti-inflammatory drugs for osteoarthritis and rheumatoid arthritis: the CLASS study: a randomized controlled trial. Celecoxib Long-term Arthritis Safety Study. JAMA. 2000;284(10):1247-1255.

33. Wallace JL. Nonsteroidal anti-inflammatory drugs and gastroenteropathy: the second hundred years. Gastroenterology. 1997; 112(3): 1000-1016.

34. Wright JM. The double-edged sword of COX-2 selective NSAIDs. CMAJ. 2002;167(10):1131-1137.

35. Deschner J, Hofman CR, Piesco NP, Agarwal S. Signal transduction by mechanical strain in chondrocytes. Curr Opin Clin Nutr Metab Care. 2003;6(3):289-293.

36. Westacott CI, Urban JP, Goldring MB, Elson CJ. The effects of pressure on chondrocyte tumor necrosis factor receptor expression. Biorheology. 2002;39(1-2):125-132.

37. Laufer S. Role of eicosanoids in structural degradation in osteoarthritis. Curr Opin Rheumatol. 2003;15(5):623-627. 
38. Pantano C, Reynaert NL, van der Vliet A, Janssen-Heininger YM. Redox-sensitive kinases of the nuclear factor-kappaB signaling pathway. Antioxid Redox Signal. 2006;8(9-10):1791-1806.

39. Bonizzi G, Piette J, Merville MP, Bours V. Cell type-specific role for reactive oxygen species in nuclear factor-kappaB activation by interleukin-1. Biochem Pharmacol. 2000;59(1):7-11.

40. Vincenti MP, Brinckerhoff CE. Early response genes induced in chondrocytes stimulated with the inflammatory cytokine interleukin1beta. Arthritis Res. 2001;3(6):381-388.

41. Kopp EB, Ghosh S. NF-kappa B and rel proteins in innate immunity. Adv Immunol. 1995;58:1-27.

42. Baldwin AS. The transcription factor NF-kB and human disease. J Clin Invest. 2001;107:3-6.

43. Perkins ND. Integrating cell-signaling pathways with NF-kappaB and IKK function. Nat Rev Mol Cell Biol. 2007;8(1):49-62.

44. Pahl HL. Activators and target genes of rel/NF-kappaB transcription factors. Oncogene. 1999;18(49):6853-6866.

45. Scheiman JM. Outcomes studies of the gastrointestinal safety of cyclooxygenase-2 inhibitors. Cleve Clin J Med. 2002;69 Suppl 1: SI40-S146.

46. Celotti F, Laufer S. Anti-inflammatory drugs: new multitarget compounds to face an old problem. The dual inhibition concept. Pharmacol Res. 2001;43:429-436.

47. Hudson N, Balsitis M, Everitt S, Hawkey CJ. Enhanced gastric mucosal leukotriene B4 synthesis in patients taking non-steroida anti-inflammatory drugs. Gut. 1993;34:742-747.

48. Rainsford KD. Leukotrienes in the pathogenesis of NSAID-induced gastric and intestinal mucosal damage. Inflamm Res. 1993;39 Suppl 1:C24-C26.

49. Obase Y, Matsuse H, Shimoda T, Haahtela T, Kohno S. Pathogenesis and management of aspirin-intolerant asthma. Treat Respir Med. 2005;4(5):325-336.

50. Babu KS, Salvi SS. Aspirin and asthma. Chest. 2000;118(5):1470-1476.

51. Berti F, Rossoni G, Magni F, et al. Nonsteroidal antiinflammatory drugs aggravate acute myocardial ischemia in the perfused rabbit heart: a role for prostacyclin. J Cardiovasc Pharmacol. 1988;12(4):438-444.

52. Marcouiller P, Pelletier JP, Guévremont M, et al. Leukotriene and prostaglandin synthesis pathways in osteoarthritic synovial membranes: regulating factors for interleukin 1 beta synthesis. J Rheumatol. 2005;32(4):704-712.

53. Sprecher HW, Baykousheva SP, Luthria DL, Mohammed BS. Differences in the regulation of biosynthesis of 20- versus 22-carbon polyunsaturated fatty acids. Prostaglandins Leukot Essent Fatty Acids. 1995;52(2-3):99-101.

54. Lippiello L, Walsh T, Fienhold M. The association of lipid abnormalities with tissue pathology in human osteoarthritic articular cartilage. Metabolism. 1991;40(6):571-576.

55. Lippiello L. Lipid and cell metabolic changes associated with essential fatty acid enrichment of articular chondrocytes. Proc Soc Exp Biol Med. 1990;195(2):282-227.

56. Plumb MS, Aspden RM. High levels of fat and (n-6) fatty acids in cancellous bone in osteoarthritis. Lipids Health Dis. 2004;3:12.

57. Xu H, Watkins BA, Adkisson HD. Dietary lipids modify the fatty acid composition of cartilage, isolated chondrocytes and matrix vesicles. Lipids Health Dis. 1994;29:619-625.

58. Hart DJ, Doyle DV, Spector TD. Association between metabolic factors and knee osteoarthritis in women: the Chingford Study. J Rheumatol. 1995;22(6):1118-1123.

59. McAlindon T, Zhang Y, Hannan M, et al. Are risk factors for patellofemoral and tibiofemoral knee osteoarthritis different? J Rheumatol. 1996;23(2):332-337.

60. Morgan SL, Baggott JE, Moreland L, Desomond R, Kendrach A. The safety of flavocoxid, a medical food, in the dietary management of knee osteoarthritis. J Med Food. 2008;12:1-6.

61. Jia Q. Generating and screening a natural product library for cyclooxygenase and lipoxygenase dual inhibitors. Stud Nat Prod Chem. 2003;29:643-718.
62. Blobaum AL, Marnett LJ. Structural and functional basis of cyclooxygenase inhibition. J Med Chem. 2007;50(7):1425-1441.

63. Dietz R, Nastainczyk W, Ruf HH. Higher oxidation states of prostaglandin $\mathrm{H}$ synthase. Rapid electronic spectroscopy detected two spectral intermediates during the peroxidase reaction with prostaglandin G2. Eur J Biochem. 1988;171(1-2):321-328.

64. Burnett BP, Jia Q, Zhao Y, Levy RM. A medicinal extract of Scutellaria baicalensis and Acacia catechu acts as a dual inhibitor of cyclooxygenase and 5-lipoxygenase to reduce inflammation. $J$ Med Food. 2007;10(3):442-451.

65. Kulmacz RJ, Lands WE. Stoichiometry and kinetics of the interaction of prostaglandin $\mathrm{H}$ synthase with anti-inflammatory agents. $J$ Biol Chem. 1985;260(23):12572-12578.

66. Callan OH, So OY, Swinney DC. The kinetic factors that determine the affinity and selectivity for slow binding inhibition of human prostaglandin $\mathrm{H}$ synthase 1 and 2 by indomethacin and flurbiprofen. J Biol Chem. 1996;271(7):3548-3554.

67. Altavilla D, Squadrito F, Bitto A, et al. Flavocoxid, a dual inhibitor of cyclooxygenase and 5-lipoxygenase, blunts pro-inflammatory phenotype activation in endotoxin stimulated macrophages. Brit $J$ Pharmacol. 2009;157(8):1410-1418.

68. Schafer H, Schafer A, Kiderlen AF, Masihi KN, Burger R. A highly sensitive cytotoxicity assay based on the release of reporter enzymes, from stably transfected cell lines. J Immunol Methods. 1997;204(1):89-98.

69. Maron DM, Ames BN. Revised methods for the Salmonella mutagenicity test. Mutat Res. 1983;113:173-215.

70. Gatehouse D, Haworth S, Cebula T, et al. Recommendations for the performance of bacterial mutation assays. Mutat Res. 1994;312:217-233.

71. Moody GC, Griffin SJ, Mather AN, McGinnity DF, Riley RJ. Fully automated analysis of activities catalyzed by the major human liver cytochrome P450 (CYP) enzymes: assessment of human CYP inhibition potential. Xenobiotica. 1999;29(1):53-75.

72. Burnett BP, Silva S, Mesches MH, Jia Q. Safety evaluation of a combination, defined extract of Scutellaria baicalensis and Acacia catechu. J Food Biochem. 2007;31:797-825.

73. Michalets EL. Update: clinically significant cytochrome P-450 drug interactions. Pharmacotherapy. 1998;18:84-112.

74. Thummel KE, Wilkinson GR. In vitro and in vivo drug interactions involving human CYP3A. Annu Rev Pharmacol Toxicol. 1998;38:389-430.

75. Freireich EJ, Gehan EA, Rall DP, Schmidt LH, Skipper HE Quantitative comparison of toxicity of anticancer agents in mouse, rat, hamster, dog, monkey, and man. Cancer Chemother Rep. 1966;50(4):219-244.

76. Elliott GA, Purmalis A, Vandermeer DA, Denlinger RH. The propionic acids. Gastrointestinal toxicity in various species. Toxicol Pathol. 1988;16(2):245-250

77. Parmar NS, Parmar S. Anti-ulcer potential of flavonoids. Indian J Physiol Pharmacol. 1998;42(3):343-351.

78. Escrig V, Ubeda A, Ferrandiz ML, et al. Variabilin: a dual inhibitor of human secretory and cytosolic phospholipase A2 with anti-inflammatory activity. J Pharmacol Exp Ther. 1997;282(1): 123-131.

79. Carlson RP, O'Neill-Davis L, Chang J, Lewis AJ. Modulation of mouse ear edema by cyclooxygenase and lipoxygenase inhibitors and other pharmacologic agents. Inflamm Res. 1985;17(2): 197-204

80. Burnett BP, Stenstrom KK, Baarsch MJ, Swafford WS, Ehrenzweig J, Levy RM. A flavonoid mixture, dual inhibitor of cyclooxygenase and 5-lipoxygenase enzymes, shows superiority to glucosamine/chondroitin for pain management in moderate osteoarthritic dogs. Intern $J$ Appl Res Vet Med. 2009;7(1):1-12.

81. Gee JM, DuPont MS, Rhodes MJ, Johnson IT. Quercetin glucosides interact with the intestinal glucose transport pathway. Free Radic Biol Med. 1998;25(1):19-25. 
82. Manach C, Morand C, Texier O, et al. Quercetin metabolites in plasma of rats fed diets containing rutin or quercetin. J Nutr. 1995; 125(7):1911-1922.

83. Hollman PC, Katan MB. Absorption, metabolism, and health effects of dietary flavonoids in man. Biomed Pharmacother. 1997; 51(8):305-310.

84. Gee JM, DuPont MS, Day AJ, Plumb GW, Williamson G, Johnson IT. Intestinal transport of quercetin glycosides in rats involves both deglycosylation and interaction with the hexose transport pathway. J Nutr. 2000;130(11):2765-2771.

85. Boulton DW, Walle UK, Walle T. Extensive binding of the bioflavonoid quercetin to human plasma proteins. J Pharm Pharmacol. 1998;50(2):243-249.

86. Akao T, Kawabata K, Yanagisawa E, et al. Baicalin, the predominant flavone glucuronide of Scutellariae radix, is absorbed from the rat gastrointestinal tract as the aglycone and restored to its original form. J Pharm Pharmacol. 2000;52(12):1563-1568.

87. Falany CN. Enzymology of human cytosolic sulfotransferases. FASEB J. 1997;11(4):206-216.

88. Piskula MK, Terao J. Accumulation of (-)-epicatechin metabolites in rat plasma after oral administration and distribution of conjugation enzymes in rat tissues. J Nutr. 1998;128(7):1172-1178.

89. Koster H, Halsema I, Scholtens E, Knippers M, Mulder GJ. Dose-dependent shifts in the sulfation and glucuronidation of phenolic compounds in the rat in vivo and in isolated hepatocytes. The role of saturation of phenolsulfotransferase. Biochem Pharmacol. 1981;30(18):2569-2575.

90. Piskula MK. Soy isoflavone conjugation differs in fed and fooddeprived rats. J Nutr. 2000;130(7):1766-1771.

91. Yim JS, Kim YS, Moon SK, et al. Metabolic activities of ginsenoside Rb1, baicalin, glycyrrhizin, and geniposide to their bioactive compounds by human intestinal microflora. Biol Pharm Bull. 2004;27(10):1580-1583.

92. Manach C, Scalbert A, Morand C, Rémésy C, Jiménez L. Polyphenols: food sources and bioavailability. Am J Clin Nutr. 2004; 79(5):727-747.

93. Wang LQ, Meselhy MR, Li Y, et al. The heterocyclic ring fission and dehydroxylation of catechins and related compounds by Eubacterium sp. strain SDG-2, a human intestinal bacterium. Chem Pharm Bull (Tokyo). 2001;49(12):1640-1643.

94. Das NP, Griffiths LA. Studies on flavonoid metabolism. Metabolism of (+)-[14C] catechin in the rat and guinea pig. Biochem J. 1969;115(4):831-836.

95. Hackett AM, Griffiths LA, Broillet A, Wermeille M. The metabolism and excretion of $(+)-[14 \mathrm{C}]$ cyanidanol-3 in man following oral administration. Xenobiotica. 1983;13(5):279-286.

96. Bell JR, Donovan JL, Wong R, et al. (+)-Catechin in human plasma after ingestion of a single serving of reconstituted red wine. Am J Clin Nutr. 2000;71(1):103-108.

97. Abe K, Inoue O, Yumioka E. Biliary excretion of metabolites of baicalin and baicalein in rats. Chem Pharm Bull (Tokyo). 1990;38(1):209-211.

98. Lai MY, Hsiu SL, Chen CC, Hou YC, Chao PD. Urinary pharmacokinetics of baicalein, wogonin, and their glycosides after oral administration of Scutellariae radix in humans. Biol Pharm Bull. 2003;26(1):79-83.

Nutrition and Dietary Supplements

\section{Publish your work in this journal}

Nutrition and Dietary Supplements is an international, peer-reviewed, open access journal focusing on research into nutritional requirements in health and disease, impact on metabolism and the identification and optimal use of dietary strategies and supplements necessary for normal growth and development. The journal welcomes papers covering
99. Lin YS, Tsai YJ, Tsay JS, Lin JK. Factors affecting the levels of tea polyphenols and caffeine in tea leaves. J Agric Food Chem. 2003; 51(7):1846-1873.

100. Ross JA, Kasum CM. Dietary flavonoids: bioavailability, metabolic effects, and safety. Annu Rev Nutr. 2002;22:19-34.

101. Fiorani M, Accorsi A, Cantoni O. Human red blood cells as a natural flavonoid reservoir. Free Radic Res. 2003;37(12):1331-1338.

102. Fiorani M, Accorsi A. Dietary flavonoids as intracellular substrates for an erythrocyte trans-plasma membrane oxidoreductase activity. Br J Nutr. 2005;94(3):338-345.

103. Tang Y, Zhu H, Zhang Y, Huang C. Determination of human plasma protein binding of baicalin by ultrafiltration and high-performance liquid chromatography. Biomed Chromatogr. 2006;20(10):1116-1119.

104. Diniz A, Escuder-Gilabert L, Lopes NP, Villanueva-Camanas RM, Sagrado S, Medina-Hernandez MJ. Characterization of interactions between polyphenolic compounds and human serum proteins by capillary electrophoresis. Anal Bioanal Chem. 2008;391(2):625-632.

105. Ishihara M, Honma M, Kuno E, Watanabe M, Koda Y. [Combination use of kampo-medicines and drugs affecting intestinal bacterial flora]. Yakugaku Zasshi. 2002;122(9):695-701.

106. Xing J, Chen X, Sun Y, Luan Y, Zhong D. Interaction of baicalin and baicalein with antibiotics in the gastrointestinal tract. J Pharm Pharmacol. 2005;57(6):743-750.

107. Toda M, Okubo S, Hara Y, Shimamura T. [Antibacterial and bactericidal activities of tea extracts and catechins against methicillin resistant Staphylococcus aureus]. Nippon Saikingaku Zasshi. Sep 1991;46(5):839-845. Japanese.

108. Iinuma M, Tanaka T, Mizuno M, Yamamoto H, Kobayashi Y, Yonemori S. Phenolic constituents in Erythrina $\mathrm{x}$ bidwilli and their activity against oral microbial organisms. Chem Pharm Bull (Tokyo). 1992;40(10):2749-2752.

109. Kuroyanagi M, Arakawa T, Hirayama Y, Hayashi T. Antibacterial and antiandrogen flavonoids from Sophora flavescens. J Nat Prod. 1999;62(12):1595-1599.

110. Kubo M, Matsuda H, Tanaka M, et al. Studies on Scutellariae radix. VII. Anti-arthritic and anti-inflammatory actions of methanolic extract and flavonoid components from Scutellariae radix. Chem Pharm Bull (Tokyo). 1984;32(7):2724-2729.

111. Yamada H, Takuma N, Daimon T, Hara Y. Gargling with tea catechin extracts for the prevention of influenza infection in elderly nursing home residents: a prospective clinical study. J Altern Complement Med. 2006;12(7):669-672.

112. Levy R, Saikovsky R, Shmidt E, Khokhlov A, Burnett BP. Flavocoxid is as effective as naproxen for managing the signs and symptoms of osteoarthritis of the knee in humans: a short-term randomized, doubleblind pilot study. Nutr Res. 2009;29(5):298-304.

113. Pillai L, Burnett BP, Levy RM. Open-label, post-marketing study of flavocoxid, a novel dual pathway inhibitor anti-inflammatory agent of botanical origin: the GOAL study. Curr Med Res Opin. 2010; 26(5):1055-1063.

\section{Dovepress}

original research, basic science, clinical \& epidemiological studies, reviews and evaluations, guidelines, expert opinion and commentary, case reports and extended reports. The manuscript management system is completely online and includes a very quick and fair peer-review system, which is all easy to use. 